\title{
Metode sinkronisasi : medan gravitasi, medan listrik dan medan magnet dalam proses pembelajaran fisika SMA
}

\author{
M. Yasin Kholifudin \\ SMA Negeri 2 Kebumen \\ Jl. Cincin Kota No. 8 Kebumen \\ Surat-e: by_fis@yahoo.co.id
}

Dalam proses pembelajaran fisika tidak lepas dari fenomena alam dalam kehidupan sehari-hari. Kemampuan menghubungkan antar konsep dan daya ingat pesera didik dalam mempelajari konsep; medan gravitasi, medan listrik dan medan magnet rendah sehingga dalam menyelesaikan probelamatika fisika mengalami kendala dan berimbas pada hasil belajar fisika rendah. Untuk dapat mengatasi hal tersebut penulis memberikan solusi dalam pembelajaran yaitu menerapkan konsep berpikir metode sinkronisasi dalam pembelajaran dengan 3 tahapan berpikir; I) analisis konsep, 2). menghubungkan antara konsep dasar secara komprehensip, dan 3) aplikatif, pada materi medan gravitasi, medan listrik dan medan magnet. Dengan konsep berpikir metode sinkronisasi dalam pembelajaran ketiga konsep tersebut peserta didik merasakan situasi belajar yang menyenangkan, mudah mengingat kembali, dan mampu menemukan hubungan berbagai hal dalam menyelesaikan problematika ketiga konsep dengan katagori soal HOTS.

The Physics learning materials stated in syllabus are closely related with natural phenomena in everyday life. Those are interconnected one another. The students' ability to connect among the materials consept; gravitational field, electric field and magnetic field is inevitably needed for their better understanding of the materials. In fact, this is lour, and this results in their low achievement. To cope with this problem the writer sets forth the so called synchronization method, a way of thingking consisting three stages i.e; analysing the concept of the materials, connecting wholly among the materials, and applying both in the learning processes. The students' applying the syncronization method during learning processes they are eased at understanding the learning materials and easily recall the materials and funally they learn physic with fun. Besides they are able to solve physics problem in HOTS level.

Kata kunci: sinkronisasi, medan gravitasi, medan listrik, medan magnet

\section{Pendahuluan}

Peserta didik SMA banyak mengalami kendala dalam belajar menerima konsep dasar maupun konsep yang komplek yang mengandung beberapa konsep fisika yang dipelajarinya. Itu semua disebabkan peserta didik dalam proses berpikir belum kritis dan kreatif dalam memaknai konsep-konsep fisika yang dipelajarinya dengan kata lain proses berpikirnya masih sepotong-sepotong tidak terjadi interkoneksi dalam pemikiran. Ilmu fisika memerlukan logika dan penalaran yang baik agar dapat mencerna, memproses, membedakan, menganalisis konsep-konsep fisika melalui pemodelan, persamaan, satuan, serta aplikatif dalam kehidupan sehari-hari.
Proses pembelajaran fisika sepenuhnya diarahkan pada pengembangan ketiga ranah secara utuh holistik, artinya pengembangan ranah yang satu tidak bisa dipisahkan dengan ranah lainnya. Dengan demikian proses pembelajaran secara utuh melahirkan kualitas pribadi yang mencerminkan keutuhan penguasaan sikap, pengetahuan dan ketrampilan [I]. Pada Kurikulum 20I3, silabus mata pelajaran fisika kompetensi KI-3 materi Medan Gravitasi yaitu 3.8 Menganalisis keteraturan gerak planet dalam tatasurya berdasarkan hukum-hukum Newton dengan materi: Hukum Newton tentang gravitasi: Gaya gravitasi antar partikel; Kuat medan gravitasi dan percepatan gravitasi; Hukum Keppler. Kompetensi KI-3 materi Medan Listrik yaitu 3.2 Menganalisis muatan listrik, gaya listrik, kuat medan listrik, fluks, potensial listrik, energi 
potensial listrik serta penerapannya pada berbagai kasus dengan materi; listrik statis (elektrostatika): listrik statis dan muatan listrik, hukum coulomb, medan listrik, energi potensial listrik dan potensial listrik, capasitor Kompetensi KI-3 materi Medan Magnet yaitu 3.3 Menganalisis medan magnetik, induksi magnetik, dan gaya magnetik pada berbagai produk teknologi dengan materi Medan Magnet: Medan magnetik di sekitar arus listrik, Gaya magnetik, Penerapan gaya magnetik [2].

Dimensi pengetahuan peserta didik yaitu memiliki pengetahuan faktual, konseptual, prosedural, dan metakognitif pada tingkat teknis, spesifik, detail, dan kompleks berkenan dengan I. Ilmu pengetahuan, 2 teknologi, 3 seni, 4 budaya, dan 5 hunaniora. Mampu mengaitkan pengetahuan di atas dalam konteks diri sendiri, keluarga, sekolah, masyarakat dan lingkungan alam sekitar, bangsa, negara, serta kawasan regional dan internasional [3].

Pada pembelajaran fisika materi medan listrik $E$ dan medan magnet $B$ peserta didik sebagian besar untuk memahami konsep masih bersifat teks book artinya kerangka berpikir peserta didik masih bersifat menghapal. Jika diberi kasus problematika yang saling berhubungan dengan konsep materi lain akan mengalami kesulitan sehingga prestasi belajar peserta didik rendah. Untuk membatu peserta didik kelas XII IPA dalam memahami konsep yang sedang dipelajarinya solusinya adalah guru membuat skema pola berpikir perserta didik untuk menghubungkan antar kosep yang terdapat pada problematika tersebut. Misalnya peserta didik diajak mengkontruksikan kembali konsep medan gravitasi $g$ sudah dipelajari di kelas X IPA dengan mengsinkronkan konsep medan listrik $E$ kemudian juga mensinkronkan dengan konsep medan magnet $\boldsymbol{B}$ yang sedang dipelajarinya di kelas XII IPA. Metode sinkronisasi konsep medan gravitasi, medan listrik dan medan magnet dilakukan pada proses pembelajaran di kelas XII IPA sebagai upaya agar peserta didik kelas XII IPA SMA Negeri 2 Kebumen memudahkan dalam berpikir bahwa satu konsep dengan konsep yang lain saling berhubungan sehingga para peserta didik dalam menyelesaikan problematika fisika tingkat tinggi HOTS secara komprehensip sesuai dengan kaidah konsep fisika.

\section{Kajian Pustaka}

\section{Medan Gravitasi}

Dalam jagat raya alam semesta ciptaan Alloh SWT susunan planet yang bergerak dengan sangat teratur pada masing-masing orbitnya. Antara Planet satu dengan yang lain dalam keadaan seimbang terjadi gaya tarik menarik Jika suatu benda jatuh dari atas permukaan bumi, maka benda tersebut jatuh menuju ke bumi hal tersebut bumi mempunyai medan gravitasi yang mampu memberikan gaya tarik yang besarnya sebanding dengan kedua massa dan berbanding terbalik dengan kuadrat jaraknya diukur dari pusat massa. Suatu benda di atas permukaan bumi akan jatuh menuju ke bumi, kasus tersebut didefinisikan sebagai berikut;

$$
F=G \frac{M m}{r^{2}}
$$

dimana $G$ adalah konstanta gravitasi umum Newton sebesar 6,67 $\mathrm{IO}^{11} \mathrm{Nm}^{2} \mathrm{~kg}^{-2}$, M massa bumi satuan $\mathrm{kg}, \mathrm{m}$ massa benda satuan $\mathrm{kg}$ dan $G \frac{M}{r^{2}}$ adalah percepatan gravitasi $g$ sehingga diperoleh persamaan

$$
F=g m
$$

Dengan tiap-tiap titik di dalam ruang di dekat bumi maka kita dapat mengasosiasikan sebuah vektor medan gravitasi $g$. Vektor ini adalah percepatan gravitasi yang akan dialami oleh sebuah benda uji (test body) yang ditempatkan pada titik tersebut dan dilepaskan. Jika m adalah massa benda dan $F$ adalah gaya gravitasi yang bekerja pada benda tersebut, maka $g$ diberikan oleh

$$
g=\frac{F}{m}
$$

Satuan kuat medan gravitasi $g$ adalah $\mathrm{N} \mathrm{kg}^{-1}$ atau $\mathrm{m} \mathrm{s}^{-2}$ $[4][5]$.

\section{Medan Listrik}

Fenomena sebuah balon yang tak bermuatan digesekkan pada baju switer, ternyata balon bermuatan listrik negatif $[-\mathrm{q}]$ dan baju switer menjadi bermuatan positif $[+q]$. Jika balon di geser menjauh kemudian dilepas balon akan bergerak ke baju switer. Jika ada dua balon yang sama, maka kedua balon akan saling menjauh. Besarnya gaya tarik-menarik dan tolak menolak keduanya sebanding dengan kedua muatan dan berbanding terbalik dengan kuadrat jaraknya diukur dari pusat titik muatan listrik dapat dituliskan dengan persamaan.

$$
F=k \frac{q_{1} q_{2}}{r^{2}}
$$

dimana $k=\frac{1}{4 \pi \varepsilon_{0}}=$ konstanta kelistrikan $9.10^{9} \mathrm{~N}^{2} \mathrm{~m}^{2} \mathrm{C}^{-2}$, $\varepsilon_{0}=$ permitivitas ruang hampa $8,85 \mathrm{IO}^{-12} \mathrm{C}^{2} \mathrm{~N}^{-1} \mathrm{~m}^{-2}$ dan $k \frac{q}{r^{2}}$ adalah kuat medan listrik $E$ sehingga diperoleh persamaan

$$
\begin{aligned}
& F=E q \\
& E=\frac{F}{q}
\end{aligned}
$$


Satuan kuat medan listrik adalah $\mathrm{NC}^{-1}$ atau volt $\mathrm{m}^{-1}$ dan $q$ merupakan muatan uji yang bermuatan $(+)$ di titik tersebut. Untuk mendifinisikan medan listrik secara operasional, Dengan menempatkan sebuah muatan uji yang kecil $q O$ yang positif pada titik di dalam ruang yang akan diselidiki gaya listrik $F$ (jika ada) yang bekerja pada benda ini $[4][5]$.

\section{Medan Magnet}

Dua buah kawat sejajar yang berarus listrik $i$ yang terpisahkan sejauh a, maka kedua kawat saling mendekati dengan gaya $F$ jika arah arus searah dan saling menjauhi dengan gaya $F$ jika arah arus berlawanan yang besarnya dituliskan dengan persamaan;

$$
F_{12} \equiv \frac{\mu o i_{1} i_{2} l}{2 \pi a}
$$

dimana $\mu o$ adalah permeabilitas kemagnetan $4 \pi \mathrm{I0}^{-7} \mathrm{Nm}^{2}$ $\mathrm{C}^{-2}$ dan $\frac{\mu o i_{1}}{2 \pi a}$ adalah kuat medan magnet $B$ sehingga diperoleh persamaan

$$
\begin{aligned}
& F_{12} \equiv B i l \sin \alpha \\
& B \equiv \frac{F_{12}}{i l \sin \alpha}
\end{aligned}
$$

Satuan kuat medan magnet $B$ adalah Tesla (T) [4][5].

Pada kondisi medan lemah gaya gravitasi memiliki bentuk yang analogi dengan gaya elektromegnetik, sehingga melalui analogi tersebut dapat diajukan suatu rumusan yang disebut dengan efek gravitoelektromagnetisme, Layankanya medan eletromagnetik, gravitasi juga diprediksi memiliki medan gravitoelektrik dan medan gravitomagnetik [6]. Hal tersebut menunjukan bahwa medan gravitasi $g$, medan listrik $E$ dan magnet $B$ saling berkaitan satu sama lain sehingga mempunyai kesamaan atau analog yang sinkron.

\section{Kuat Medan: [g], [E], dan [B]}

Konsep untuk medan gravitasi $g$ didapatkan di sekitar massa benda $M$, medan listrik $E$ didapatkan di sekitar muatan listrik $q$, medan magnet $B$ didapatkan di sekitar kawat berarus listrik i dengan demikian di sekitar massa benda ada medan gravitasi $\boldsymbol{g}$, di sekitar muatan listrik ada medan listrik $E$ dan di sekitar kawat berarus listrik ada medan magnnet $B$. Semakin jauh dari pusat massa, muatan listrik, kawat berarus listrik diperoleh medan gravitasi $\boldsymbol{g}$, medan listrik $E$, medan magnetik $B$ semakin lemah atau kecil dan ketiganya merupakan besaran vektor.

Definisi medan gravitasi $g$ sangat mirip atau sinkron dengan definisi medan listrik $E$, dan medan magnet $B$, kecuali bahwa massa benda uji dan bukan muatannya adalah sifat yang dipergunakan untuk mendifinisikan medan gravitasi tersebut satuannya $\mathrm{ms}^{-2}$ dapat juga $\mathrm{Nkg}^{-1}$, satuan kuat medan listrik $E$ adalah $\mathrm{NC}^{-1}$ dan satuan medan magnet $B$ adalah Tesla atau $\mathrm{NC}^{-1} \mathrm{~m}^{-1} \mathrm{~s}^{-1}, \mathrm{NA}^{-1} \mathrm{~m}^{-1}$ atau weber $\mathrm{m}^{-2}$. Jadi $g, E$, dan $B$ dinyatakan sebagai sebuah gaya dibagi oleh sebuah sifat (massa atau muatan atau arus) benda uji tersebut.

\section{Gaya dan Hukum}

Jika ada dua buah benda bermassa $\mathrm{M}_{1}$ dan $\mathrm{M}_{2}$ terpisah dengan jarak r, maka kedua benda akan tarik-menarik atau tolak menolak yang dinamakan gaya tarik gravitasi $F$ yang dikenal dengan Hukum Gravitasi Umum Newton. Jika ada dua buah muatan listrik $q_{I}$ dan $q_{2}$ terpisah dengan jarak $r$, maka kedua muatan listrik akan tarik-menarik atau tolak menolak dengan gaya elektrostatika $F$ yang dikenal Hukum Coulomb. Jika ada dua buah kawat berarus listrik iı dan i2 sejajar terpisah dengan jarak $r$, maka kedua kawat akan tarik menarik atau tolak menolak dengan gaya lorentz $F$ yang dikenal dengan Hukum Ampere

\section{Potensial}

Konsep potensial grafitasi $V_{\boldsymbol{g}}$ didapatkan di sekitar massa $M$, potensial listrik $V_{E}$ didapatkan di sekitar muatan listrik $Q$, medan magnet $B$ didapatkan di sekitar kawat berarus listrik i dengan demikian di sekitar massa ada potensial gravitasi $\boldsymbol{V g}$, di sekitar muatan listrik ada potensial listrik $V_{E}$. Semakin jauh dari pusat massa, muatan listrik, diperoleh potensial gravitasi $V \boldsymbol{g}$, potensial listrik $V_{E}$, semakin kecil dan keduanya merupakan besaran skalar.

\section{Hukum Gauss}

Jumlah garis medan listrik yang melalui sebuah permukaan sebanding dengan jumlah muatan netto $\phi$ yang ada di dalam permukaan tersebut

$$
\begin{aligned}
& \phi_{\text {netto }}=\frac{Q}{\varepsilon_{0}} \\
& E A \cos \theta=\frac{Q}{\varepsilon_{0}}
\end{aligned}
$$

\section{Hukum Ampere}

Untuk semua bentuk lintasan tertutup yang mengelilingi penghantar berarus I di dalam vakum, medan magnetik yang ditimbulkan memenuhi persamaan hukum Ampere

$$
\oint B d l \cos \theta=\mu_{0} I
$$

Dengan elemen $\mathrm{dl}$ adalah elemen panjang lintasan tertutup, $\theta$ adalah sudut antara arah induksi magnetik $B$ dengan $\mathrm{dl}$, dan I adalah kuat arus listrik total yang dilingkupi oleh lintasan tertutup. 


\section{Metode Penelitian}

Metode penelitan melalui kajian studi pustaka dan pengalaman penulis dalam proses pembelajaran fisika kelas di kelas XII IPAI SMA Negeri 2 Kebumen. Metode sinkronisasi untuk konsep medan gravitasi, medan listrik dan medan magnet dilakukan pada proses pembelajaran di kelas XII IPAI dengan sintak pembelajaran I) peserta didik melakukan literasi konsep medan gravitasi, medan listrik medan magnet, 2) guru dan siswa terlibat aktif diskusi dan tanya jawab medan gravitasi, medan listrik, medan magnet, 3) guru bersama peserta didik mensinkronkan medan listrik $E$ dengan medan gravitasi $g$, medan magnet $B$ dengan 4 ) peserta didik mencatat hasil sinkronisasinya. 5) peserta didik menerapkan konsep tersebut sebagai upaya agar peserta didik kelas XII IPAI SMA Negeri 2 Kebumen memudahkan dalam berpikir bahwa satu konsep dengan konsep yang lain saling berhubungan sehingga para peserta didik dalam menyelesaikan problematika fisika tingkat tinggi dapat menyelesaikan secara komprehensip.

\section{Hasil Penelitian dan Pembahasan}

Tabel I. Metode sinkronisasi konsep besaran medan gravitasi, medan listrik, medan magnetik.

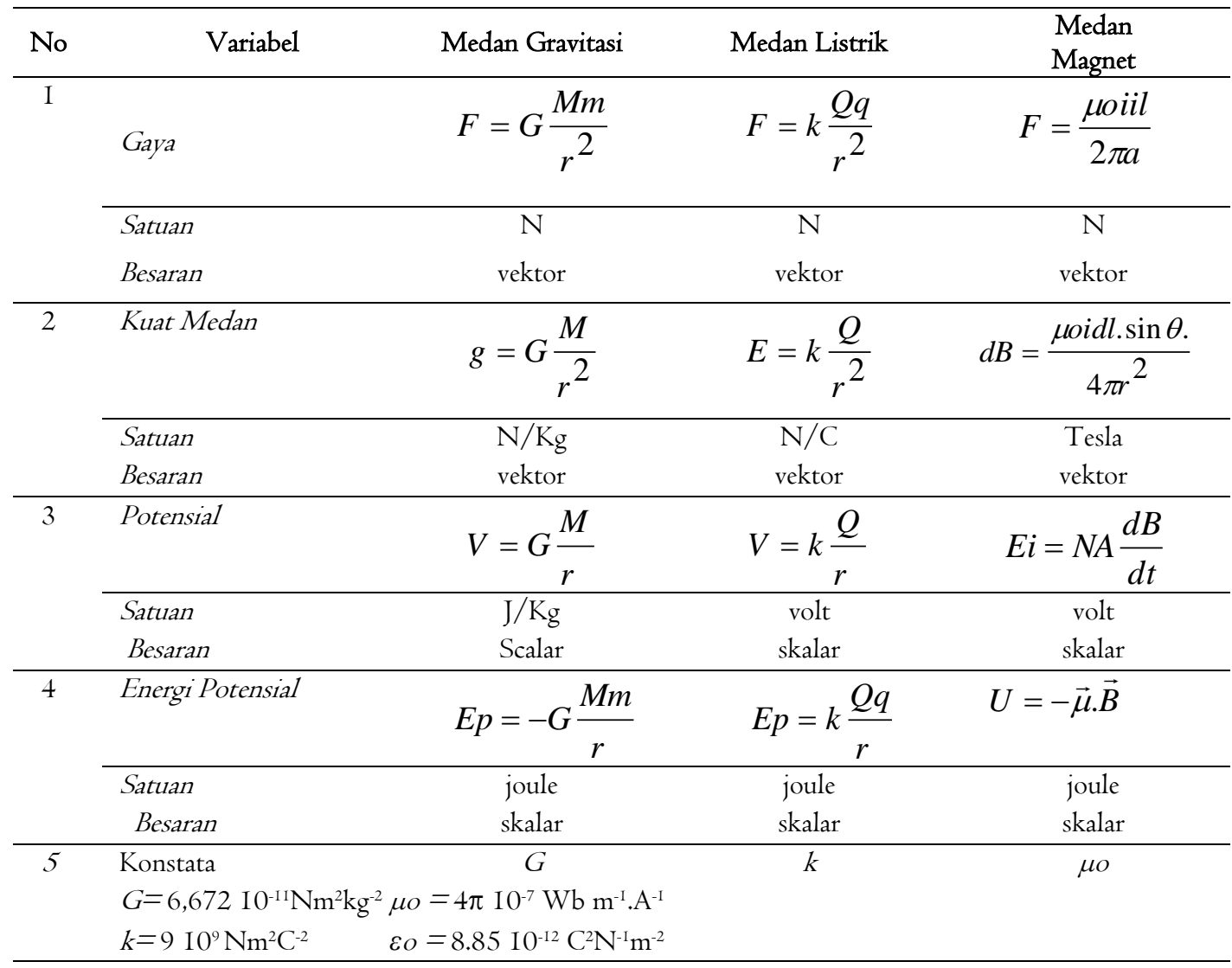

Tabel I di atas merupakan hasil isian proses pembelajaran peserta didik melalui kegiatan literasi, diskusi, tanya jawab pada konsep medan gravitasi, medan listrik, medan magnet.

\section{Aplikasi dalam Pembelajaran Fisika}

\section{Kasus I}

Pada materi Gelombang Elektromagnetik: perpaduan antara medan magnet $B$ dan medan listrik $E$ dimana medan magnet dan medan listrik saling tegak lurus merambat ke segala arah dengan persamaan

$$
\mathbf{B}=\mathbf{B}_{\max } \sin \omega t \text { dan } \mathbf{E}=\mathbf{E}_{\max } \sin \omega t
$$

\section{Hubungan E dan B}

Jika muatan listrik q berada dalam medan listrik $E$, maka muatan listrik tersebut mendapat gaya coulomb $F_{c}$ dan jika muatan q berada dalam medan magnet $B$ bergerak dengan kelajuan $\mathcal{c}$, maka muatan listrik tersebut mendapat gaya lorentz $F_{L}$. Persamaan yang dihasilkan sebagai berikut;

$$
\begin{aligned}
& F_{\text {coulomb }}=F_{\text {lorentz }} \\
& E q=B q c \\
& c=\frac{E}{B}
\end{aligned}
$$


Metode sinkronisasi : medan gravitasi, medan listrik dan medan magnet dalam proses pembelajaran fisika SMA

Intensitas gelombang elektromagnetik yang dipancarkan memenuhi persamaan

$$
I=\frac{P}{4 \pi r^{2}}=\frac{E_{\max } B_{\max }}{2 \mu_{0}}
$$

\section{Kasus 2}

Percobaan Tetes Milikan yaitu percobaan tetes-tetes minyak masuk ke dalam daerah medan listrik $E$ antara anoda dan katode, dengan beda potensial $V$ di antara kedua plat yang berjarak $d$, tetes minyak tersebut bergerak dengan kelajuan konstan $v$ atau dalam keadaan seimbang, sehingga berlaku persamaan;

$$
\begin{aligned}
& \sum F=0 \\
& F_{\text {coulomb }}=W_{\text {gravitasi }} \\
& E q=m g \\
& \frac{V}{d} q=m g
\end{aligned}
$$

Jika tetes minyak milikan mula-mula diam kemudian bergerak ke atas dengan percepatan konstan a, maka berlaku persamaan

$$
\begin{aligned}
& S_{t}=\frac{1}{2} a t^{2} \\
& \sum F=m a \\
& F_{\text {coulomb }}-W_{\text {gravitasi }}=m a \\
& E q-m g=m a \\
& \frac{V}{d} q-m g=m a
\end{aligned}
$$

\section{Kasus 3}

Jika kawat sejajar horizontal yang berarus listrik $i$ mempunyai massa persatuan panjang $m / 1$, agar kedua kawat tetap sejajar pada jarak yang sama a, maka berlaku persamaan

$$
\begin{aligned}
& \sum F=0 \\
& F_{\text {Lorentz }}-W_{\text {gravitasi }}=0 \\
& F_{12}-m g=0 \\
& \frac{\mu_{0} i_{1} i_{2} l}{2 \pi a}=m g
\end{aligned}
$$

\section{Kasus 4}

Seberkas sinar katoda dipercepat pada beda potensial listrik $V$ masuk tegak lurus pada medan magnet $B$, maka besar kecepatan $v$ berlaku persamaan ;

$$
E K_{\text {mekanik }}=E K_{\text {listrik }}
$$

$$
\begin{aligned}
& \frac{1}{2} m v^{2}=q V \\
& v^{2}=\frac{2 q V}{m}
\end{aligned}
$$

Kemudian sinar katoda bergerak masuk tegak lurus medan magnet diperoleh persamaan berikut:

$$
\begin{aligned}
& F_{\text {lerentz }}=F_{\text {sentripetal }} \\
& B q v \sin \alpha=m \frac{v^{2}}{r} \\
& B q \sin 90^{\circ}=m \frac{v}{r}
\end{aligned}
$$

Persamaan (I5) di masukan ke persamaan (I6) diperoleh jari-jari lintasan sinar katoda r adalah

$$
r=\sqrt{\frac{2 V m}{B q}}
$$

Besar tenaga parrtikel yang dihasilkan tergantung jari-jari $r$

$$
\begin{aligned}
& r=\frac{m v}{q B} \\
& v=\frac{q B r}{m}
\end{aligned}
$$

Maka tenaga kinetik adalah

$$
K=\frac{1}{2} m v^{2}=\frac{q^{2} B^{2} r^{2}}{2 m}
$$

\section{Kasus 5}

Percobaan Thomson seberkas sinar katoda q dipercepat pada beda potensial listrik $V$ kemudian masuk tegak lurus pada medan magnet $B$ dan medan listrik $E$, maka perbandingan muatan persatuan massa elektron $[\mathrm{e} / \mathrm{m}]$ diperoleh dari persamaan berikut:

$$
\begin{aligned}
& E_{k_{\text {mekanik }}}=E_{k_{\text {listrik }}} \\
& \frac{1}{2} m v^{2}=q V \\
& \frac{e}{m}=\frac{v^{2}}{2 V}
\end{aligned}
$$

Hubungan $E$ dan $B$ adalah $v=e / b$ Sehingga persamaannya menjadi

$$
\begin{aligned}
& \frac{e}{m}=\frac{\frac{E^{2}}{B^{2}}}{2 V} \\
& \frac{e}{m}=\frac{E^{2}}{2 V B^{2}}
\end{aligned}
$$


Tabel 2. Tingkat penguasan konsep pada peserta didik

\begin{tabular}{cccc}
\hline \multirow{2}{*}{ Kasus } & \multicolumn{3}{c}{ Tingkat Penguasan Konsep } \\
\cline { 2 - 4 } & Tinggi & Sedang & Rendah \\
\hline I & $40 \%$ & $51 \%$ & $9 \%$ \\
2 & $40 \%$ & $57 \%$ & $3 \%$ \\
3 & $51 \%$ & $43 \%$ & $6 \%$ \\
4 & $57 \%$ & $40 \%$ & $3 \%$ \\
5 & II\% & $74 \%$ & $14 \%$ \\
\hline Jumlah & $40 \%$ & $53 \%$ & $7 \%$ \\
\hline
\end{tabular}

Pada tabel 2 di atas diperoleh data tingkat penguasaan kompetensi konsep pada sampel 35 peserta didik. Pada kasus 5 diperoleh tingkat penguasan katagori sedang dengan komposisi $74 \%$ sedang dan rendah I4\% artinya logika berpikir dalam menggabungkan konsep untuk problematika tersebut diperlukan konsep berpikir yang tinggi yang memerlukan analitis yang tajam. Pada kasus 3 dan 4 diperoleh tingkat penguasan konsep peserta didik dengan katagori tinggi dalam menyelesaikan problematika, ini menunjukan peserta didik mampu menggunakan konsep berpikir analogi, menggabungkan, dan menghubungkan konsep medan listrik, medan magnet, medan gravitasi untuk menyelesaikan problematika. Hal tersebut sesuai dengan hasil penelitian yang menyatakan analogi memainkan peran vital dalam proses pembelajaran yang kreatif dan inovatif oleh guru sains, serta pelatihan ketrampilan berpikir kritis, logis, dan analitis [7]. Secara keseluruhan dari 5 kasus diperoleh tingkat penguasan kompetensi 35 peserta didik dengan katagori tinggi $40 \%$, sedang $53 \%$, dan rendah $7 \%$, menggambarkan peserta didik dapat menerima dengan baik metode sinkronisasi konsep medan gravitasi, medan listrik, dan medan magnet dalam pembelajaran di kelas serta dapat melatih ketrampilan berpikir yang analitis dan kreatif dalam menyelesaikan problematika materi fisika.

\section{Kesimpulan}

Melalui proses pembelajaran fisika pada konsep medan gravitasi, medan listrik dan medan magnet dengan menggunakan proses berpikir metode sinkronisasi dengan tahapan berpikir; analisis konsep, menghubungkan antara konsep dasar secara komprehensip dan aplikatif. diperoleh simpulan situasi belajar yang menyenangkan, terbangunnya konsep berpikir yang kritis dan kreatif pada peserta didik yang mampu menghubungan antar konsep dalam berbagai hal problematika, konsep mudah diingat kembali, sehingga dapat menyelesaian problematika soal dengan katagori soal HOTS. Penulis menyarankan kepada rekan guru yang menerapkan metode ini peserta didik harus diajak fokus berkonsentrasi pikiran dan logika bernalar sehingga problematika fisika yang rumit dapat terselesaikan dengan benar.

\section{Kepustakaan}

[I] Permendikbud No. 22 Tahun 2016 tentang Standar Proses Pembelajaran, 2016

[2] Permendikbud No. 24 Tahun 2016, silabus Fisika SMA, 2016

[3] Permendikbud No 20 SKL Tahun 2016. Standar Kompetensi Untuk Satuan Pendidikan dasar dan Menengah, 2016

[4] Sears dan Zemansky, Fisika Universitas Edisi kesepuluh Jilid I, Erlangga 200I

[5] Halliday-Resenick, Patur Silaban, Erwin Sucipto, Fisika Edisi Ke 3 Jilid 2, Erlangga 1999

[6] Yuant Tiandho, Koreksi Gaya Gravitasi dan efek gravitoelektromagnetisme Berdasarkan Entropi Gravitasi Kuantum, Jurnal Matematika, Saint dan Teknologi UT, Volume 18, Nomor 2, September 2017, 95-I05

[7] Tjipto Prastowo, Strategi Pengajaran Sains dengan Analogi Suatu Metode Alternatif Pengajaran Sains Sekolah, Jurnal Penelitian Fisika dan Aplikatif (JPFA) Unnesa, Volume I, Juni 2011 